\title{
Usability of Context-Aware Mobile Educational Game
}

\section{Chris Lu}

School of Computing and Information Systems

Athabasca University

1 University Drive Athabasca, AB T9S 3A3 Canada

E-mail: chrischien630@gmail.com

\section{Maiga Chang*}

School of Computing and Information Systems

Athabasca University

1 University Drive Athabasca, AB T9S 3A3 Canada

E-mail:maiga@ms2.hinet.net

\section{Kinshuk}

School of Computing and Information Systems

Athabasca University

1 University Drive Athabasca, AB T9S 3A3 Canada

E-mail:kinshuk@athabascau.ca

\section{Echo Huang}

Department of Information Management National Kaohsiung First University

No 2 Jhuoyue Rd., Nanzih District, Kaohsiung City 811, Taiwan

E-mail: echoh@nkfust.edu.tw

\section{Ching-Wen Chen}

Department of Information Management National Kaohsiung First University

No 2 Jhuoyue Rd., Nanzih District, Kaohsiung City 811, Taiwan

E-mail: chingwen@nkfust.edu.tw

*Corresponding author

\footnotetext{
Abstract: Ubiquitous learning is an innovative approach that combines mobile learning and context-awareness, can be seen as kind of location-based services, first detects user's location, knows surrounding context, and gets learning profile, and then provides the user learning materials accordingly. Game-based learning have become an emerging research topic and been proved that can increase users' motivations and interests. The aim of our research is to present a context-awareness multi-agent-based mobile educational game that can generate a series of learning activities for users doing On-the-Job training and
} 
make users interact with specific objects in their working environment. We reveal multi-agent architecture (MAA) into the mobile educational game design to achieve the goals of developing a lightweight, flexible, and scalable game on the platform with limited resources such as mobile phones. A scenario with several workplaces, research space, meeting rooms, and a variety of items and devices in 11th floor of a university's building is used to demonstrate the idea and mechanism proposed by this research. At the end, a questionnaire is used to examine the usability of the proposed game. 37 freshmen participate in this pilot study and the results show that they are interested in using the game and the game does help them getting familiar with the new environment.

Keywords: Context-Awareness; Knowledge Structure; Game-Based Learning; Situated Learning; Multi-Agents System; Mobile Phone; Usability

Biographical notes: Chris Lu is a graduate student in the School of Computing Information and Systems, Athabasca University (AU), Athabasca, Alberta, Canada. He is also a research assistant at the project of iCORE - Adaptivity and Personalization in Informatics, Canada. His research interest involves Gamebased learning, mobile computing, learning management systems and distributed systems.

Maiga Chang received his Ph. D from the Dept. of Electronic Engineering from the Chung-Yuan Christian University in 2002. He is Assistant Professor in the School of Computing Information and Systems, Athabasca University (AU), Athabasca, Alberta, Canada. His researches mainly focus on mobile learning and ubiquitous learning, museum e-learning, game-based learning, educational robots, learning behavior analysis, data mining, intelligent agent technology, computational intelligence in e-learning, and mobile healthcare. He serves several peer-reviewed journals as editorial board members. He has participated in 130 international conferences/workshops as a Program Committee Member and has (co-)authored more than 134 book chapters, journal and international conference papers. In September 2004, he received the 2004 Young Researcher Award in Advanced Learning Technologies from the IEEE Technical Committee on Learning Technology (IEEE TCLT). He is a valued IEEE member for fourteen years and also a member of ACM, AAAI, INNS, and Phi Tau Phi Scholastic Honor Society.

Kinshuk is NSERC/iCORE/Xerox/Markin Industrial Research Chair for Adaptivity and Personalization in Informatics, Associate Dean of Faculty of Science and Technology, and Full Professor in the School of Computing and Information Systems at Athabasca University, Canada. His work has been dedicated to advancing research on the innovative paradigms, architectures and implementations of mobile and ubiquitous learning systems for personalized and adaptive learning in increasingly global environments. With more than 300 research publications in refereed journals, international refereed conferences and book chapters, he is frequently invited as keynote or principal speaker in international conferences ( 22 in past 5 years). He was awarded the prestigious fellowship of Japan Society for the Promotion of Science in 2008. He has also served on review panels for grants for the governmental funding agencies of various countries, including the European Commission, Austria, Canada, Hong Kong, Italy, the Netherlands, Qatar, Taiwan and the United States. He also has a successful record of procuring external funding over 11 million Canadian dollars as principal and co-principal investigator. He is Founding Chair of IEEE Technical Committee on Learning Technologies, and Founding Editor of the Educational Technology \& Society Journal (SSCI indexed with Impact Factor of 1.067 according to Thomson Scientific 2009 Journal Citations Report). 
Echo Huang is an associate professor in the Department of Information Management, National Kaohsiung First University of Sci. \& Tech., Taiwan. Her received her $\mathrm{PhD}$ from the National Cheng Kung University in Taiwan. Her papers have appeared in EC-related journals such as Internet Research, Human and Computers Behaviors, Electronic Commerce Research and Applications, and Journal of Electronic Commerce in Organizations. Her research interests include electronic business, electronic government, online consumer behaviors, technology acceptance, Web 2.0 and Internet marketing.

Ching-Wen Chen is a Professor in the Department of Information Management and the Director of IMBA program at the National Kaohsiung First University of Science and Technology, Taiwan. He earned a Ph.D. in Production and Operations Management (Area of Information Systems and Quantitative Sciences) from Texas Tech University and an MBA from Oklahoma State University. His researches include management of information systems, quality management, knowledge management and managerial decision-making. Dr. Chen's articles have appeared in journals such as Information \& Management, Total Quality Management \& Business Excellence, Quality \& Quantity, Quality Engineering, International Journal of Quality \& Reliability Management, Engineering Economist, Expert Systems with Applications, Journal of Electronic Commerce in Organizations, Journal of Marine Science and Technology and International Journal of Innovative Computing, Information and Control.

\section{Introduction}

According to the statistics in 2010, vendors and manufacturers can produce and sell more than three hundred millions smartphones and have 72 percent increasing from 2009 to 2010, moreover, smartphones occupied 19 percents of total mobile communications device sales in 2010 (Pettey \& Goasduff, 2011). These statistics data shows the rapidly growing of smartphone market and indicates the changes of using mobile phones. In the foreseeable future, most of people in workplace will have at least one smartphone. More and more applications are developed on smartphones for business assistance, entertainment, education, communication, and so forth. With the mobile platform features such as portability, multi-media capacity, wireless Internet access, and location-aware potential (Kim \& Schliesser, 2007), mobile applications are widely used and bring the opportunities to various domains in our daily life including education, transportation, healthcare, tourism, and training. The circumstance creates a huge potential benefit to On-the-Job Training (OJT). For instance, people can learn the procedure of operating machines in front of the equipment and read the policy in time on their smartphones instead of attending the orientation. The development of mobile OJT systems then helps new employees learn the required knowledge and skills ubiquitously in their daily working environment as well as help employers save the education and training costs.

Brown and colleagues (1989) argue that students can learn specific knowledge more efficiently by interacting with authentic environment such as learning English vocabulary in the zoo (Brown, Collins, \& Duguid, 1989). Many researchers use mobile devices to make students have feelings that they are living in the era or the place in which they can obtain the knowledge, e.g. the users can learn rainforest plants and ecology in Amazon River zone of botanic garden, that is so-called mobile/ubiquitous learning (Chang \& Chang, 2006; Chen, Kao, Yu, \& Sheu, 2004; Kurti, Milrad, \& Spikol, 2007; $\mathrm{Wu}$, Yang, Hwang, \& Chu, 2008). Some other researchers develop mobile games for 
educational purpose; these games not only make learners doing learning activities in specific environment such as solving missions in museums and historical sites, but also make them get motivated if compared with abovementioned mobile learning systems (Chang, Wu, Chang, \& Heh, 2008; Wu, Chang, Chang, Yen, \& Heh, 2010).

However, most of the existing research on mobile learning and game-based learning focus on specific discipline in educational settings (i.e. school campus, museum or historical site) only. The learning systems proposed in abovementioned educational settings usually deliver knowledge of natural science, art, and history. On the other hand, knowledge and skills also exist in our daily life and working environment, for instances, understanding the purchasing procedure and using photocopy machine, thus, people need to learn before they are required to complete specific tasks. Hence, an educational system for multi-disciplines and on-the-job training is necessary to design and develop. The proposed mobile educational game also needs to consider the different roles that users may play due to different positions in a company usually require different orientation courses for the on-the-job training, for instances, HR staff may need to know hiring process and learn how to use job-posting system, at meanwhile, Accounting staff need to know purchasing procedure and policy and learn how to use assessment management system.

In addition, smartphones have limited computing power and resources compared to desktop and laptop computers, the smartphone applications hence are usually small and simplified. Tan and Kinshuk (2009) have proposed five design principles for developing applications on mobile devices: multiplatform adaption, little resource usage, little human/device interaction, small data communication bandwidth usage, and no additional hardware. These design principles take the limited computing power and resources that mobile devices such as smartphones have into considerations. The software architecture design in this research then becomes an important issue to us when we design and develop the context-aware mobile educational game.For instance, not all smartphones have built-in GPS receiver, and even those smartphones have GPS receivers will encounter difficulty in sensing where the users are at and what context is surrounding the users inside buildings and in a cloudy day. A mobile system shouldn't ask users to purchase new smartphones or additional hardware for using it.

In this research, we propose a context-awareness mobile educational game under multi-agent architecture to meet three requirements existed while learning with smartphones: (1) makes camera-embedded smartphones be the context-awareness learning platform; (2). provides users personalized contents and/or services based on their locations and surrounding context; and, (3) comply the design principles of mobile application development (Tan \& Kinshuk, 2009).

This research has four objectives to deal with the multi-discipline, the on-the-job training, and the mobile application design issues as well as to verify the usability of the proposed mobile educational game: (1) deploying two-dimensional barcode scanner to smartphones, so that the phones have ability to identify where the user is by reading the information stored in the barcode; (2) generating learning activities automatically according to the user's location and the surrounding contexts, so that s/he can interact with the objects which may represent specific knowledge/concepts and get familiar with the environment via doing the activities; (3) designing and implementing a multi-agentbased mobile game, so that different services and tasks can be divided and dispatched to different agents, in such case, not all services need to start at the very beginning; and, (4) examining the proposed game and the multi-agent architecture we designed with the usability analysis. 
This paper is organized as follows. Section 2 introduces the relevant works of knowledge structures, multi-agent systems, educational games, usability, and theories needed to use for activity generation. Section 3 describes the process of contextawareness learning activity generation with real case, i.e. 11th floor of a university's building. Section 4 presents multi-agent-based mobile educational game design including system architecture and the agent collaborations. Section 5 describes the pilot study design, analysis, results, and findings. At the end, Section 6 makes conclusions and talks about the possible further works.

\section{Knowledge Structure \& Context-Aware Mobile Educational Game}

\subsection{Ubiquitous Knowledge Structure}

In order to provide users' personalized/customized learning services, first of all, we need to know what the users want to learn and what they have already known. Knowledge structure is a good way to store and present the concept relations that learning materials may have.

Knowledge structure can be traced back to the memory model proposed by Quillian in 1967. After that, several knowledge structures are proposed to visualize concepts via graphs. Novak and Gowin (1984) have proposed a structure called concept map, which uses graph to organize and represent knowledge. The concept map uses circles or boxes for concepts, and connects two concepts with undirected line to represent concept relations. Concept maps can be used not only as learning tool but also an evaluation tool (Novak \& Cañas, 2006). Ogata and Yano (2005) have proposed a knowledge awareness map which can visualize the relations between the sharing knowledge and the learner interactions. Another well-known theoretical structure called Semantic Network which is proposed by Sowa in 1983. Semantic network is a systematic means for researchers to model an individual's mental schema of declarative knowledge (Fisher \& Hoffman, 2003). Figure 1 shows two knowledge structures.

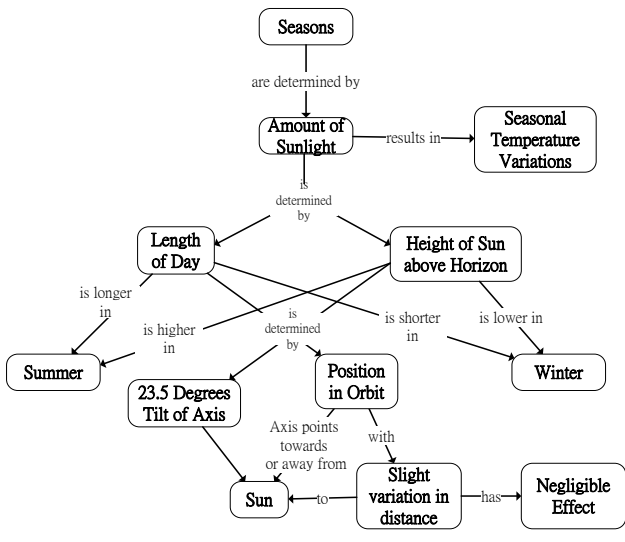

(a) Concept Map for presenting seasons (Novak \& Cañas, 2008)

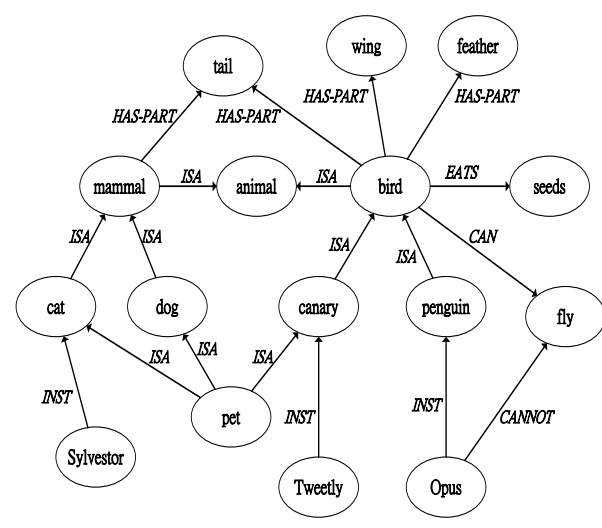

(b) Semantic Networks for presenting birds (Sowa, 1983)

Figure 1. Knowledge Structures 
The knowledge structure used in this research is context-awareness knowledge structure. $\mathrm{Wu}$ and his colleagues (2008) propose the context-awareness knowledge structure for museum learning and elementary-level botanic learning (Wu, Chang, Chang, Liu, \& Heh, 2008). It has proved as a good way to store the knowledge that learning objects in the real world may have.

This research adapts the context-awareness knowledge structure according to the learning environment that the mobile game takes place, i.e. 11th floor of a university building in which new staffs and visiting scholars reside at. Figure 2 shows the altered context-awareness knowledge structure: Domain layer defines on-the-job training requirements as well as themes. In addition, different domains may cover same objects and characteristics. Characteristic layer is a hierarchical structure and may be associated with many domains, has root characteristics and children characteristics. Object layer stores all learning objects in the real world, e.g. workplaces, equipment, devices, forms, flyers, etc.

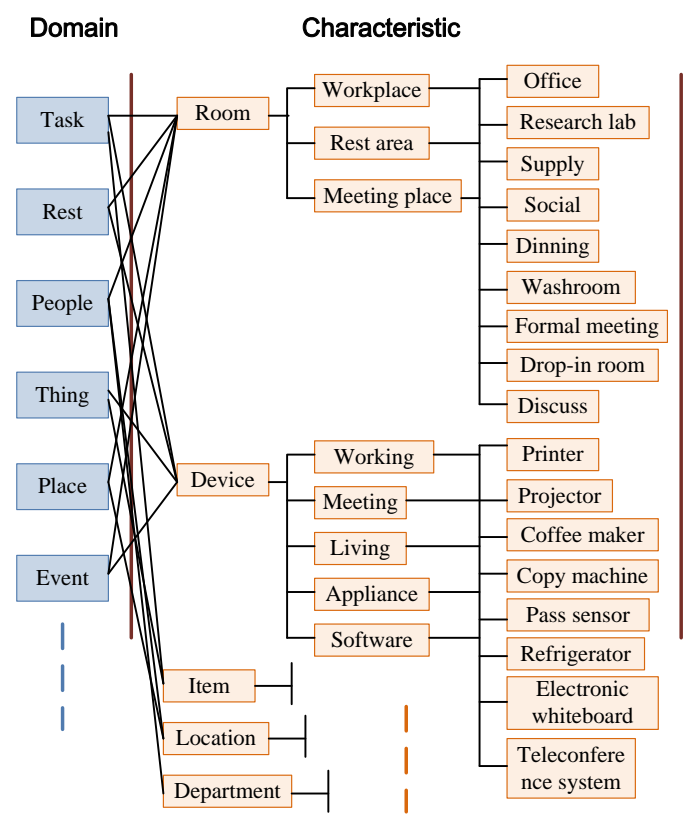

Object

\section{Figure 2. Partial context-awareness knowledge structure for the 11th floor of the university building.}

\subsection{Game Based Learning}

Game-based learning (GBL) has been used in training and education field for a while. The combination of digital games and learning materials is a new knowledge presentation form (Pivec, Dziabenko, \& Schinnerl, 2003). Correspondingly, the characteristics of games such as fantasy, curiosity, challenge and control attract players to be continuously involved in a game (Malone, 1981). Therefore, the proper GBL design may motivate users to learn and increase their learning performance. Corti (2006) lists the key benefits that GBL can provide for on-the-job training, the potential benefits include employee's skill/performance improvement, employee's awareness of his/her role and responsibility, 
induction tools for new hires, education tools for customer or partner, and motivation tools in the business.

There are many different types of games, and two of them seem to be rather suitable for educational purposes: adventure game and role-playing game (Cacallari, Hedberg, \& Harper, 1992; Frazer, Argles, \& Wills, 2008). During the adventure journey of game-play in these games, players may encounter missions, tasks, and questions. The implicit knowledge or solutions for these quests need players' judgments and reactions. The problem-solving process may positively increase players' interest, enjoyment, involvement, or confidence (Garris, Ahlers, \& Driskell, 2002). The challenges that a game gives to the players and the pleasure experiences that players gain from achievements in the game also motivate them playing continuously and foster them comprehensive understandings of domain knowledge (Corti, 2006; Garris, Ahlers, \& Driskell, 2002).

\subsection{Multi-Agent System}

Intelligent agent is independent computer programs, is capable of acting autonomous and learning continuously to meet its design objectives (Baylor, 1999). Multi-agent system is a software environment where many agents are living in it. These agents are responsible for their own tasks and collaborate with other agents whose responsibilities belong to the pre- and post-requisite tasks. Researchers have applied multi-agent concept into learning management and mobile educational system design, and have reported good results in system scalability (Dutchuk, Muhammadi, \& Lin, 2009; Zhang \& Lin, 2007).

Multi-agent-based system is one of this research's objectives, designing a system with agent-based perspective makes the mobile educational game more flexible and expandable. For instance, the system can find an agent to store user's playing data if the network is disconnected and ask another agent doing batch update when the network is available again. We talk the detailed multi-agent design for the mobile educational game in Section 4.

\subsection{Information Theory and Rough Set}

In order to measure the common/rare degree of a learning object and learning characteristic, information theory and rough set are taken into consideration.

Information theory uses logarithmic base and probability to calculate the value of a learning object/characteristic in the environment by comparing with others. Information theory is developed by Shannon in 1948. Information theory is a theoretical method of applied mathematics and electrical engineering to quantify information or signal. Some researchers use it to measure the importance of information that involved in learning objects in the real world (Liu, Kuo, Chang, \& Heh, 2008). In this research, a learning object's information value is:

$$
I\left(L O_{i}\right)=\log _{2}\left(\frac{1}{P_{L O i}}\right),
$$

where $P_{L O i}$ is the characteristic probability of the learning object $L O_{i}$ and $I\left(L O_{i}\right)$ is the information value of the learning object $L O_{i}$. 
Rough set is an approach to determine if the user is interesting in the learning objects. Rough set has been widely used in various domains: knowledge discovery decision analysis, pattern recognition, and intelligent system. Rough set has three regions which can be used to classify things into three categories (Chang, Wu, Chang, \& Heh, 2008; Düntsch, \& Gediga, 1998; Pawlak \& Skowron, 2007):

(1) Positive set: All elements within positive set fit the success criteria that the researchers made.

(2) Boundary set: All elements within boundary set cannot be classified into either Positive or Negative set easily due to its uncertainty or partial fit in the success/failed criteria.

(3) Negative set: All elements within negative set fit the failed criteria that the researchers made.

\subsection{Usability}

We use usability to evaluate if the proposed system can help users learn in the specific environment and satisfy users' needs. Usability is a general term used in human computer interaction (HCI) research and can be widely explained rather than the traditional term, "user friendliness". Nielsen (1993) has explained that usability is a quality attribute that is measured up by five components to test a system's overall acceptability. A usable system should be "easy to learn", "efficient to use", "easy to remember", "few errors", and "subjectively pleasing". The five characteristics proposed by Nielsen are generally accepted as essential of any software project (Fetaji, Dika, \& Fetaji, 2008; Holzinger, 2005; Nielsen, 1993; Seong, 2006).

- Learnability (easy to learn): Users can rapidly have some works done with the system.

- Efficiency (efficient to use): Users can not only learn how to use the system quickly, but also can have high productivity via using the system.

- Memorability (easy to remember): After a period of not having used the system, users still remember how to use the system without having to learn the instruction again.

- Errors tolerant (few errors): Users would make few errors when use the system and the errors can be easily recovered.

- Satisfaction (subjectively pleasing): Users are satisfied with the system.

The Specifications of International Standard Organization for HCI and Usability, ISO 9241-11 document, is a guidance of usability. This standard provides developers the definition of usability and tells research how to identify the necessary items such as user's performance and satisfaction while evaluating system's usability (ISO/IEC, 1998). The definition of usability described in ISO $9241-11$ is:

"Usability extents to which a product can be used by specified users to achieve specified goals with effectiveness, efficiency and satisfaction in a specified context of use."

Usability in mobile environment has been considered as an important system design and development goal. Hussain and Ferneley (2008) have reviewed the existing measurement models for usability and proposed a set of usability guidelines for mobile application development. Seong (2006) has also proposed a framework including three 
categories (i.e. user analysis, interaction, and interface design) and ten (10) guidelines for usability of mobile learning portals.

In this research, both the usability definition and the abovementioned guidelines are taken into considerations for evaluating the usability of the proposed mobile game for on-the-job training. The pilot study results and findings are described in Section 5.

\section{Methods}

In this section, we first use Chris' case to explain how the context-awareness learning activity generation process works within the proposed mobile educational game. After that, we talk the process and the methodology in details. At the end of this section, we come back to the case and use the facets and situations described in the case to show readers what learning objects are chosen and what learning activities are generated and provided to Chris.

\subsection{Individual Asynchronous Functions}

Chris is a visiting scholar who comes to the city learning centre of Athabasca University first time. In the learning centre, there are a lot of rooms for different purposes (e.g. working, meeting, drop-in, and dinning) as well as many hardware and software (e.g. printers, projectors, teleconference systems, coffee makers, banner system, and expense claim system). In order to make himself get familiar with the new research environment and everything related to what he needs for doing research in the University, he downloads and installs the Context-Aware Mobile Educational Game (CAMEG) in his smartphone with built-in camera and Wi-Fi.

Users can play two roles in this game, i.e. visiting scholar and new employee. Thus, Chris chooses to play as a visiting scholar which fits what he is right now in the University. After he chose the role, he finds that several themes which he may want to know more. Chris then chooses a theme named "Life Style in ELC" because he wants to know how to survive in this new environment before starting his research life here.

The game then generates a series of learning activities related to the chosen theme and role. These activities are not only sequential but also location-based. Each activity involves one or more learning objects including rooms, hardware, and software. Hence, he can get familiar with the environment and the facilities surround him by playing the game. For instances, he may first knows where is the kitchen and how to use the coffee machine to have a cup of coffee, and then he may understand how to setup a printer and how to operate a photocopy machine. Moreover, some activities cover the working procedure (i.e., booking a room for meeting) and University policy (i.e., applying leave for sickness and/or attending conference). He will get the knowledge/information by playing the game and doing the sequential learning activities one by one.

\subsection{Generation Flow}

In abovementioned scenario, the game uses knowledge structure to store environment information and its learning objects, furthermore, uses the activity generating engine to generate a series of learning activities. Figure 3 shows the learning activity generation flow. This flow has six steps: 
(1) Analysis: We first list the learning domains and corresponding objects which users can learn in the environment; then identify all characteristics and figure the associated learning objects out. We store this analysis result into a knowledge structure, i.e., the context-awareness knowledge structure. After that, we design two roles and several corresponding themes which cover one or more learning domains we have in the knowledge structure.

(2) Role \& theme: At this step, the user can choose one of the two roles we designed at Step 1 and choose the theme s/he wants to play.

(3) Activity generation: The game puts the choices that the user made at Step 2 into the activity generating engine to generate activities.

(4) Learning activity chain: The activity generating engine compares the learning activities and sorts it into a chain.

(5) Learn by playing: The user can follow the instructions and look for the designated learning objects to do the learning activities one by one, at meanwhile, s/he can get familiar with the environment.

(6) Personal experience update: the learning objects and related knowledge s/he has learnt will be stored in database in order to record his/her learning status (e.g. what learning activities s/he has solved and what learning objects s/he has learnt) and performance (e.g. how well s/he did in doing the learning activities and how many learning activities s/he has done).

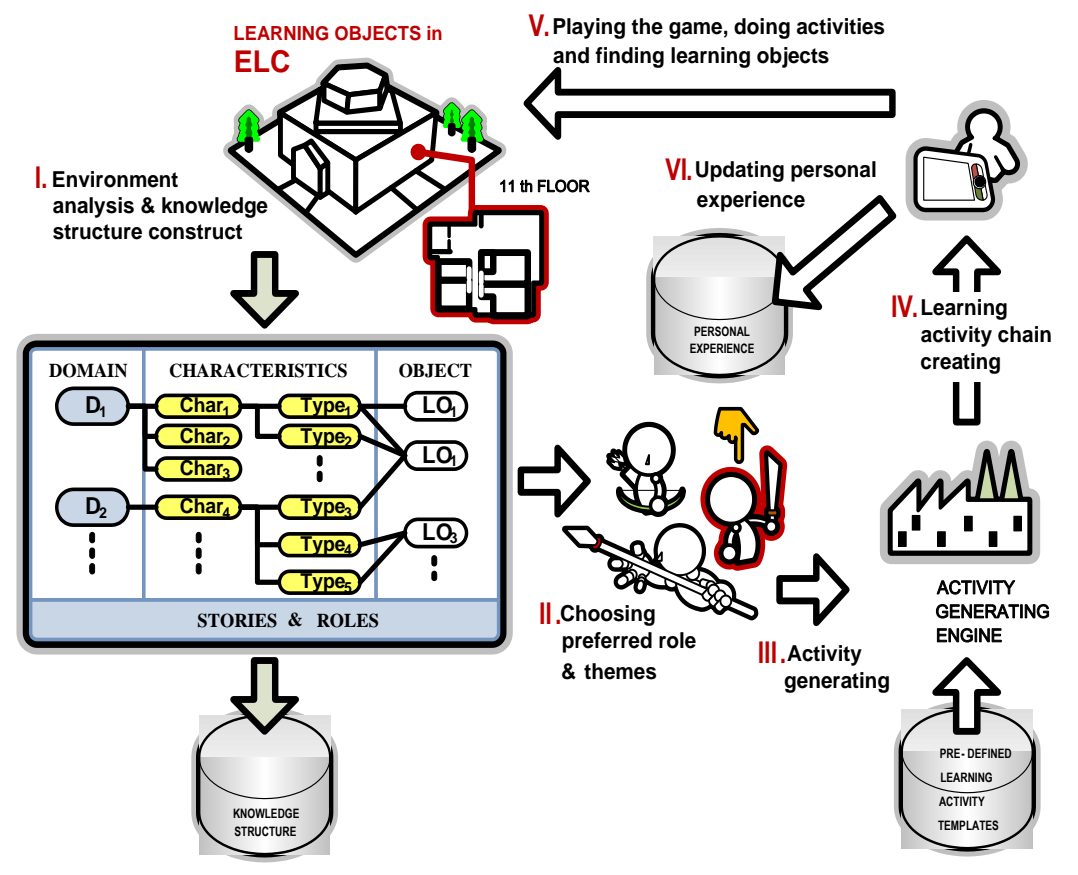

Figure 3. Learning activity generation flow

The generation flow involves two important issues: (1) How to retrieve chosentheme relevant learning objects from the knowledge structure? (2) How to generate the 
learning activities and sort it into a chain? The followed subsections talk about the solutions of these two issues.

\section{A. Finding a Set of Learning Objects}

Figure 3 has illustrated the six main steps of the learning activity generation flow from functional perspective. This subsection describes the detailed design of the activity generating engine. The generating engine has five tasks:

Task 1: Retrieving characteristics and learning objects according to the chosen theme

At the analysis step in the generation flow (as Figure 3 shows), each theme is associated with a domain and multiple themes can have relations with the same domain. For example, when Chris chooses the theme - "Life Style in ELC", the theme actually associates with the domain, "Event", which covers the frequently happened events in daily works. The engine retrieves all domain relevant learning objects and corresponding characteristics from the context-awareness knowledge structure.

Task 2: Using rough set to filter the irrelevant learning objects and characteristics to the chosen theme

The engine uses rough set to discover the necessary root characteristics for the chosen theme, and then analyzes the relations among learning objects and characteristics. Once again, take the "Life style in ELC" theme as example (as Figure 4 shows), the relevant characteristics (i.e. positive and boundary characteristics) are "Room" and "Device" and the irrelevant characteristic (i.e. negative characteristics) is "Item". The irrelevant characteristics and learning objects will not be taken into calculation further.

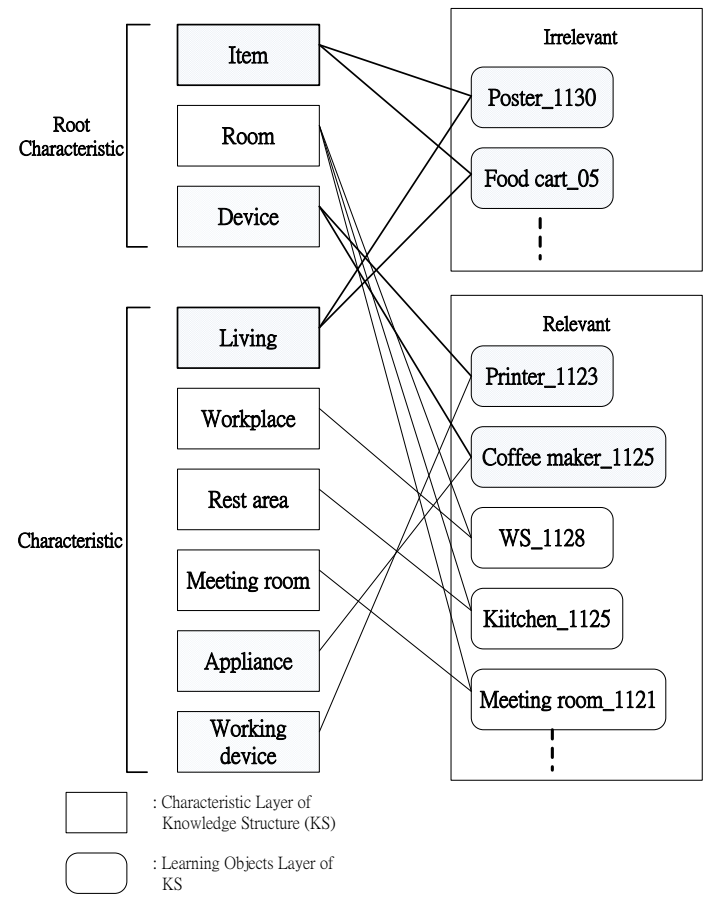

Figure 4. Relations analysis for "Life style in ELC" theme 
Task 3: Using information theory to weight all learning objects

The engine uses information theory to weight learning objects according to how many theme relevant characteristics the learning objects have. For example, the root characteristic - "Room" in Figure 5 has three characteristics: "Workplace", "Rest area", and "Meeting place"; each characteristic has three child characteristics. Meanwhile, some child characteristics such as research lab, dinning, and drop-in room may have more than one parent characteristic, because their implicit characteristics.

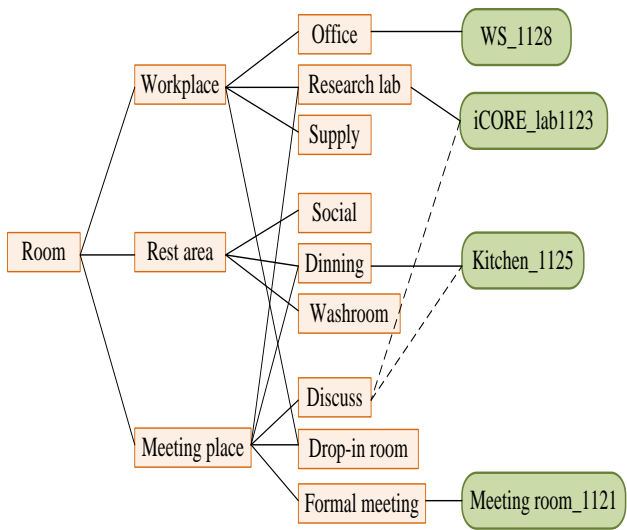

(a) Room characteristic

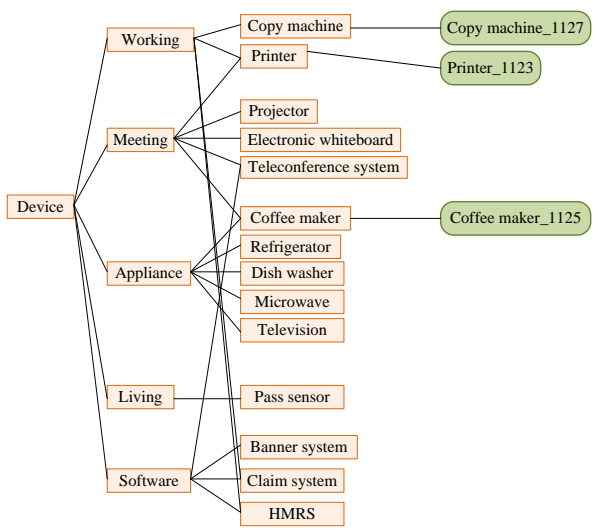

(b) Device Characteristic

Figure 5. Example of characteristic hierarchical

In order to weight the learning objects, the engine has to calculate the information value of all characteristics. The probability of a characteristic depends on which level the characteristic is at and how many siblings the characteristic has, for examples, the probability of Workplace is $1 / 3$ due to Workplace has another two siblings, Rest area and Meeting place; the probability of Discuss is $1 / 15(1 / 3 * 1 / 5)$ due to Discuss has another four siblings, Research lab, Dinning, Drop-in room, and Formal meeting:

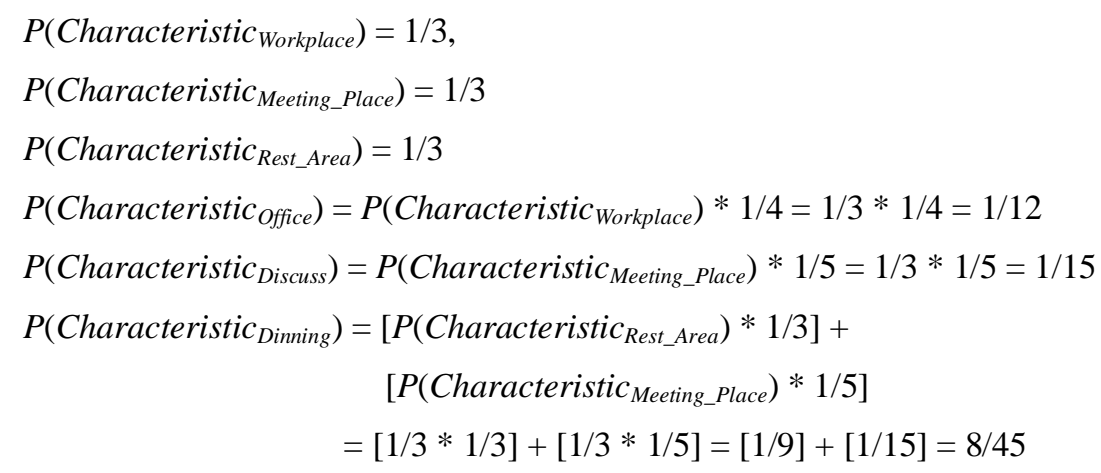

Once the engine had probability values for every characteristic, it can calculate the information values of characteristics:

$$
\begin{aligned}
& I\left(\text { Characteristic }_{\text {Office }}\right)=\log _{2}\left(1 / P\left(\text { Characteristic }_{\text {Office }}\right)\right)=\log _{2}(1 /(1 / 12))=3.5850 \\
& I\left(\text { Characteristic }_{\text {Discuss }}\right)=\log _{2}\left(1 / P\left(\text { Characteristic }_{\text {Discuss }}\right)\right)=\log _{2}(1 /(1 / 15))=3.9069 \\
& I\left(\text { Characteristic }_{\text {Dinning }}\right)=\log _{2}\left(1 / P\left(\text { Characteristic }_{\text {Dinning }}\right)\right)
\end{aligned}
$$




$$
=\log _{2}(1 /(8 / 45))=2.4919
$$

Object $_{\text {Kitchen_l125 }}$ are

$$
\begin{aligned}
& I\left(\text { Object }_{\text {WS_l128 } \left._{-}\right)=I\left(\text { Characteristic }_{\text {Office }}\right)=3.5850}\right. \\
& \begin{aligned}
I\left(\text { Object }_{\text {Kitchen_1125 }}\right) & =I\left(\text { Characteristic }_{\text {Dinning }}\right)+I\left(\text { Characteristic }_{\text {Discuss }}\right) \\
& =2.4919+3.9069=6.3988 .
\end{aligned}
\end{aligned}
$$

A learning object may have one or more characteristics. If a learning object has only one characteristic, the learning object can be seen as an object with specific function, On the contrary, the learning may be considered as a multi-function object if it has two or more characteristics. A characteristic may have one or more child characteristics as Figure 5 shows. A learning object can be considered as a simplified object if its characteristics belong to a smaller child characteristic set. Under this situation, the learning object has smaller information value due to its characteristics have a larger probability. For examples, the probability of Characteristic Office $_{\text {is }} 1 / 12$ as Eq.(1) shows. Similarly, a learning object can be considered as a diversified object if its characteristics belong to a larger child characteristic set. Under such situation, the learning object has larger information value. In this research, we assume that it is better for people doing onjob-training start from those simplified objects.

\section{B. Forming a Series of Learning Activities}

After the game weights all learning objects that are filtered and retrieved from the context-awareness knowledge structure, the game starts to generate theme relevant learning activities and selects learning objects for activities.

Task 4: Finding learning objects for pre-defined learning activity templates and generating activities

The engine has a set of pre-defined learning activity templates stored in the database. The templates are associated with one or more learning objects and characteristics, for examples, "looking for a printer" template may associate with "Characteristic Printer $_{\text {" and }}$ "having a cup of coffee in the kitchen" template may associate with "Object Coffee_Maker_1125" and "Object $_{\text {Kitchen_1125". }}$

The engine uses the characteristics and objects retrieved by Task 2 to decide whether a template could be used or not. If a template requires specific characteristic(s), the engine will generate learning activities by picking up suitable learning objects which have the required characteristics. Otherwise, the engine simply generates the activity by filling the template up with the specific learning object(s) directly. In either case, the template may have more than one instances, for example, the "looking for a printer" template may have two instances, i.e., "looking for Object $t_{\text {Printer_xerox" }}$ and "looking for Object $_{\text {Printer_hp. }}$ " At last, the engine summarizes the information values of the learning objects associated with the learning activity instances, which means, each learning activity instance has its own information value and the engine chooses one instance to represent the template.

Task 5: Generating learning activity chain based on the information values the activities have

The engine then sorts the learning activity instances generated from Task 4 based on how many learning objects the activity contains and what information value the activity has. 
In this research, the learning activities in the chain are sorted by learning object amounts and activity information values.

\subsection{Activity Generation in the Scenario}

We use the same scenario to present the whole process and possible results. After Chris decided to play as a "Visiting Scholar" and chose "Life Style in ELC" theme, the game retrieves several pre-defined learning activity templates according to the chosen role and theme and relevant learning objects and characteristics in the environment. These templates are "looking for someone's work space", "having a cup of coffee in the kitchen", "photocopy my paper in the supply room", "looking for a printer", and "looking for the meeting room".

The engine calculates the learning objects' information values:

Room: (based on Figure 5(a))

$$
\begin{aligned}
& I\left(\text { Object }_{\text {WS_I128 }}\right)=3.5850 \\
& I\left(\text { Object }_{\text {Kitchen_I125 }}\right)=6.3988 \\
& I\left(\text { Object }_{\text {Meeting room_ll21 }}\right)=\log _{2}(1 /(1 / 3 * 1 / 5))=3.9069 \\
& I\left(\text { Object }_{\text {Supply room_1126 }}\right)=\log _{2}(1 /(1 / 3 * 1 / 4))=3.5850
\end{aligned}
$$

Device: (based on Figure 5(b))

$$
\begin{aligned}
& P\left(\text { Characteristic }_{\text {Copy_Machine }}\right)=1 / 5 * 1 / 4=1 / 20 \\
& P\left(\text { Characteristic }_{\text {Coffee_maker }}\right)=[1 / 5 * 1 / 5]+[1 / 5 * 1 / 5]=2 / 25 \\
& P\left(\text { Characteristic }_{\text {Printer }}\right)=[1 / 5 * 1 / 4]+[1 / 5 * 1 / 5]=9 / 100 \\
& I\left(\text { Object }_{\text {Copy machine_l127 }}\right)=\log _{2}(1 /(1 / 20))=4.3219 \\
& I\left(\text { Object }_{\text {Coffee maker_I125 }}\right)=\log _{2}(1 /(2 / 25))=3.6439 \\
& I\left(\text { Object }_{\text {Printer_ll23 }}\right)=\log _{2}(1 /(9 / 100))=3.4739
\end{aligned}
$$

\section{Item:}

belongs to irrelevant set as Figure 4 shows.

The engine then starts to generate activities (we list partial activities below):

$$
\begin{aligned}
& \text { Activity }_{1} \text { : Looking for Characteristic } \text { Office }_{\rightarrow} \rightarrow \text { Looking for Object }_{W S_{-} 1128}
\end{aligned}
$$

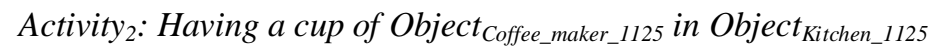

$$
\begin{aligned}
& \text { Activity }{ }_{3}: \text { Object }_{\text {Copy machine_II27 my paper in the Object }} \text { Supply room_1126 }
\end{aligned}
$$

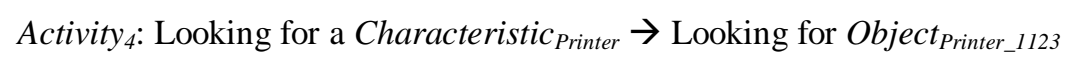

$$
\begin{aligned}
& \text { Activity }_{5} \text { : Looking for the Characteristic } \text { Meeting_room }_{1} \rightarrow \text { Not Available }
\end{aligned}
$$

The engine generates sequential activity chain based on two rules, (1) the activity involves less learning object(s) has higher priority, (2) if activities involve same amount of learning objects, the activity with lower information value has higher priority. Based 
on the two rules, Figure 6 shows the learning activity chain for "Life Style in ELC" theme below.

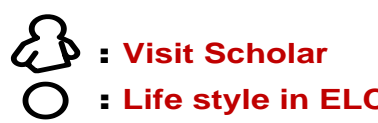

Learning Activity Chain

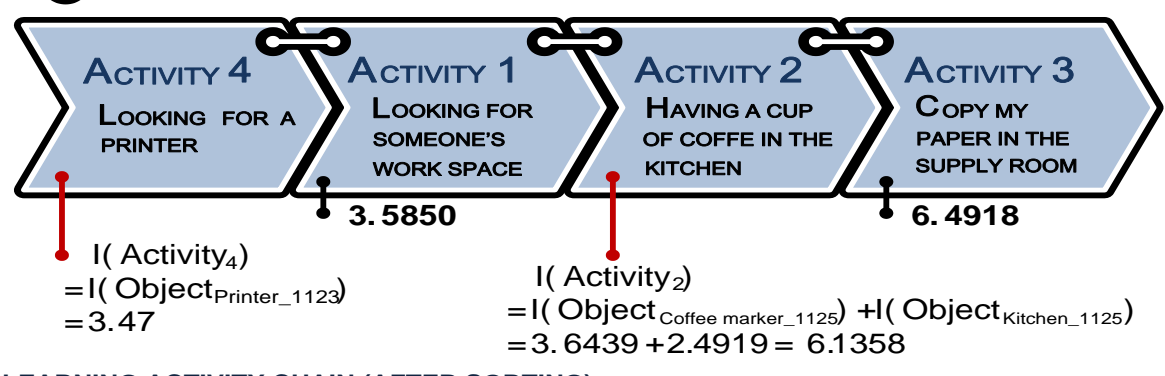

LEARNING ACTIVITY CHAIN (AFTER SORTING)

Figure 6. Learning activity chain

These learning activities are dynamically generated according to the surrounding objects, the learning objects the user has not learned yet, the role and the theme the user has chosen at the very beginning. In other words, the users may get different activities and even different activity sequence because they have different experiences and needs.

\section{Multi-Agent Mobile Educational Game Design}

\subsection{Architecture (with the diagram of system architecture)}

To develop a lightweight, flexible, and scalable mobile educational game for on-the-job training, this research takes multi-agent architecture (MAA) into considerations while designing the game. Multi-agent architecture not only makes different agents have different responsibilities, but also provides us an expandable way to develop further functions, for instances, we can put new agents into the game for special purpose or can replace an old agent with a new and more powerful one. Figure 7 shows the MAA-based system model.

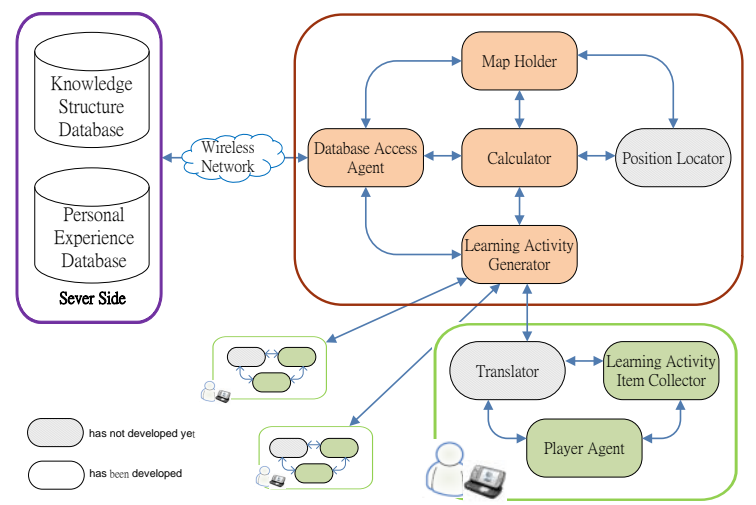

Figure 7. Multi-Agent Architecture of the proposed mobile educational game

This research has eight agents with different responsibilities and tasks: 
- Player Agent - Player agent is a bridge between the user and other agents. It gets the decisions the user made and acquires data from other agents such as Translator and Learning Activity Generator.

- Learning Activity Item Collector - Learning Activity Item Collector helps the user scan the QR code with the built-in camera, and decrypts and interprets the $\mathrm{QR}$ code. Two kinds of $\mathrm{QR}$ codes we have in this research, one stores positioning data and another one stores the knowledge and instructions that the corresponding objects may have.

- Translator - Translator can identify different language inputs and encode/decode the inputs with appropriate character set. Translator is very useful in non-English speaking country (e.g. China, India, and Japan) as well as bilingual environments (e.g. English-French and Dutch-English).

- Calculator and Learning Activity Generator - The two agents accomplish the tasks of context-awareness learning activity generation. Calculator is responsible for measuring learning objects' information values according to the chosen role, theme, and the context surrounding the user. Learning Activity Generator, on the other hand, is responsible for generating activities based on the characteristics and corresponding learning objects filtered by Calculator and resorting those activities into a chain.

- Position Locator - Position Locator is responsible for detecting where the user is. The GPS-enabled Position Locator gathers the GPS data packets from the GPS receiver and extracts the longitudes and latitudes from the packets. On the other hand, the Camera-enabled collector gets encoded data by scanning the 2dimension barcode and decodes the data stored by the 2-dimension barcode.

- Map Holder - Map Holder always keeps a copy of the map where the user is at for serving other agents when the network connection is no longer available and DB Access Agent is not able to connect to the database. The map in the proposed game is the altered context-awareness knowledge structure, altered from Ubiquitous Knowledge Structure which is proposed by $\mathrm{Wu}$ and his colleagues (Wu, et. al., 2008).

- DB Access Agent - DB Access Agent uses appropriate data manipulation language (i.e., SQL commands) to access data from the database for other agents. If the network connection is not available, the agent will tell other agents to look for Map Holder's help but keep those jobs required database update. DB Access Agent will do batch update when the network connection is recovered.

\subsection{Mobile Application Development Issues}

By applying multi-agent concept in developing the mobile educational game, we can successfully comply with the five design principles of mobile application development proposed by Tan and Kinshuk (2009).

Regarding "multiplatform adaption" design principle: The proposed game use Java Micro Edition (Java ME) as the programming language to implement most of the agents and use native programming languages to implement those agents which access low-level features and functions that smartphones provide, e.g., built-in camera. Beside the programming language, we use QR Codes to store positioning data in order to make sure that users can play the game with the smartphones which have no built-in GPS 
receiver. These designs lead the game working well on different mobile platform as long as it supports Java application.

Regarding "little resource usage" design principle, the multi-agent based educational game we developed on smartphones consumes relatively less resource since not all agents are needed to be started at the very beginning.

Regarding "little human/device interaction" design principle, in the proposed game, the Player Agent only talks to users for asking them to pick role and theme at the beginning. After that, the Player Agent gives the users a learning activity to solve and only interacts with the users again when they ask Learning Activity Item Collector to scan the QR Codes for them.

Regarding "small data communication bandwidth use" design principle, DB Access Agent and Map Holder are designed in such a way to make the mobile educational game we developed do not require network bandwidth all the time. Specifically, Map Holder will backup data from Server's database to mobile device's local Records Management System (RMS) at the starting stage, which means the game then can work without the Internet connection. Once the Internet is recovered, the game will do a batch update to synchronize data. Moreover, we use QR Codes to store the knowledge and instructions that the corresponding objects may have to reduce the system accessing the learning contents on the Internet all the time.

Regarding "no additional hardware" design principle, similar to what is done for the "multiplatform adaption", the users are neither required to have the smartphones with built-in GPS receiver nor required to purchase RFID reader for getting longitudes and latitudes where the users as well as the learning contents are associated with specific learning objects.

\subsection{Collaborations among Agents}

In this subsection, the details of the collaboration among agents are discussed. Figure 8 illustrates the relations among the agents and database. Agents communicate with each other by sending requests and receiving responses. An agent is initiated only when other agents need certain agent's help. With such flexible collaboration mechanism, it is possible to extend and enhance the game at anytime very easily by adding new agents or replacing old ones without changing the main program.

Any smartphone can host the proposed game as long as the device supports Java ME with the Mobile Information Device Profile (MIDP) 2.0 and have built-in camera and internet connections. It would be better but not necessary if the device has built-in GPS. As Figure 8 shows, the system flow includes three stages: the first stage involves three agents, the Player Agent, Translator, and DB Access Agent (step 1 and 2); the second stage focuses on the learning activity generation (step 3 to 7), which involves Learning Activity Generator, Calculator, Position Locator, Translator, and DB Access Agent; and, the third stage involves Learning Activity Item Collector, the Player Agent, Translator, and DB Access Agent (step 8 and 9). In addition, we have an agent called Map Holder which acts as the backup of DB Access Agent and keeps the copy of the database and user's profile on the smartphone in case the Internet connection is unavailable. Following paragraphs describe the three stages in details. 


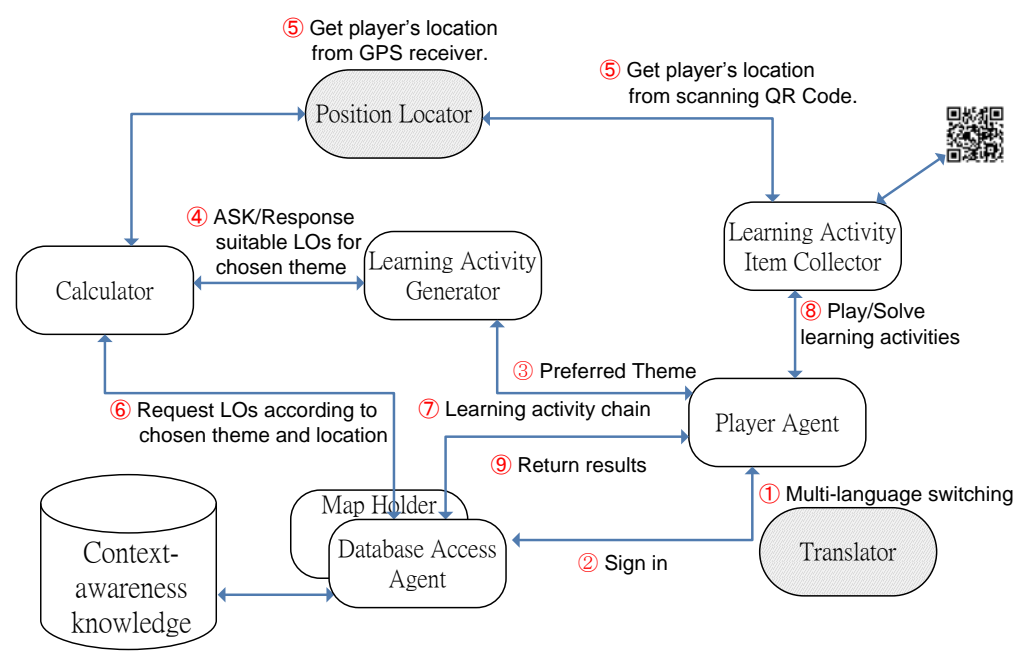

Figure 8. Working flow and collaborations among agents

\section{Stage I. User signs in/signs up for the game}

The Player Agent interacts with the user and helps data exchanges between the user and other agents. At beginning, the Player Agent gets username and password from the user and then sends these data to Translator (step 1 in Figure 8) to see what language the data uses. The Player Agent then sends user's username/password to DB Access Agent. DB Access Agent judges if the account is existed in either the game database or other system's database (e.g. our university's Moodle database). If the username/password does not exist, DB Access Agent informs the Player Agent. The Player Agent then asks the user to create an account for playing the game (step 2 in Figure 8). Map Holder is a backup of DB Access Agent; it helps other agents to retrieve required data under offline mode (i.e., when Internet connection is not available).

\section{Stage II. Context-awareness learning activity generation}

After the user signed in the game, the user can choose his/her preferred role and theme. The Learning Activity Generator receives the choices and asks Calculator for suitable learning objects and characteristics (step 3 and step 4 in Figure 8). At meantime, Position Locator starts positioning process by using either GPS (if the built-in GPS receiver has detected) or camera (step 5 in Figure 8). Once the Calculator had the location data from Position Locator and chosen theme from Learning Activity Generator, the Calculator uses information theory and rough set to find the appropriated learning objects and characteristics and to calculate the information value for each learning object and characteristic (step 6 in Figure 8). Consequently, the Learning Activity Generator received the learning objects with information values; it compares the learning objects and characteristics with learning activity templates and composes learning activities. The sorted learning activities are sent to the Player Agent (step 7 in Figure 8) to show up on the screen and to ask the user doing it.

\section{Stage III. User does learning activities}

In the beginning of this stage, Learning Activity Generator gives the Player Agent the learning activity chain (step 7 in Figure 8). The user then receives the learning activities one by one offered by the Player Agent. Each learning activity asks the user to find 
specific learning object(s) and to collect the learning objects by scanning its QR Codes. Therefore, the Player Agent helps the user to wake Learning Activity Item Collector up when the user wants to collect the learning activity item. The Learning Activity Item Collector starts the built-in camera for the user to take photo of QR Code and decodes the QR Code for the user. The Player Agent then checks whether the learning object collected by the user is what the learning activity asks for or not (step 8 in Figure 8). Finally, the user's experiences are saved back to the database via DB Access Agent or Map Holder (step 9 in Figure 8). The synchronized function let the user can see what activities s/he has done, which also means that learning activity generator will offer him/her different activity chain with other learning objects when s/he plays next time.

\subsection{Complete Example of Game Play}

Figure 9 shows the screenshots of the game-play. During the game-play, the Player Agent is the only agent who interacts with the user and helps data exchanges between the user and other agents. Correspondingly, DB Access Agent is the only agent designed to access the database to reduce the complexity of system development.

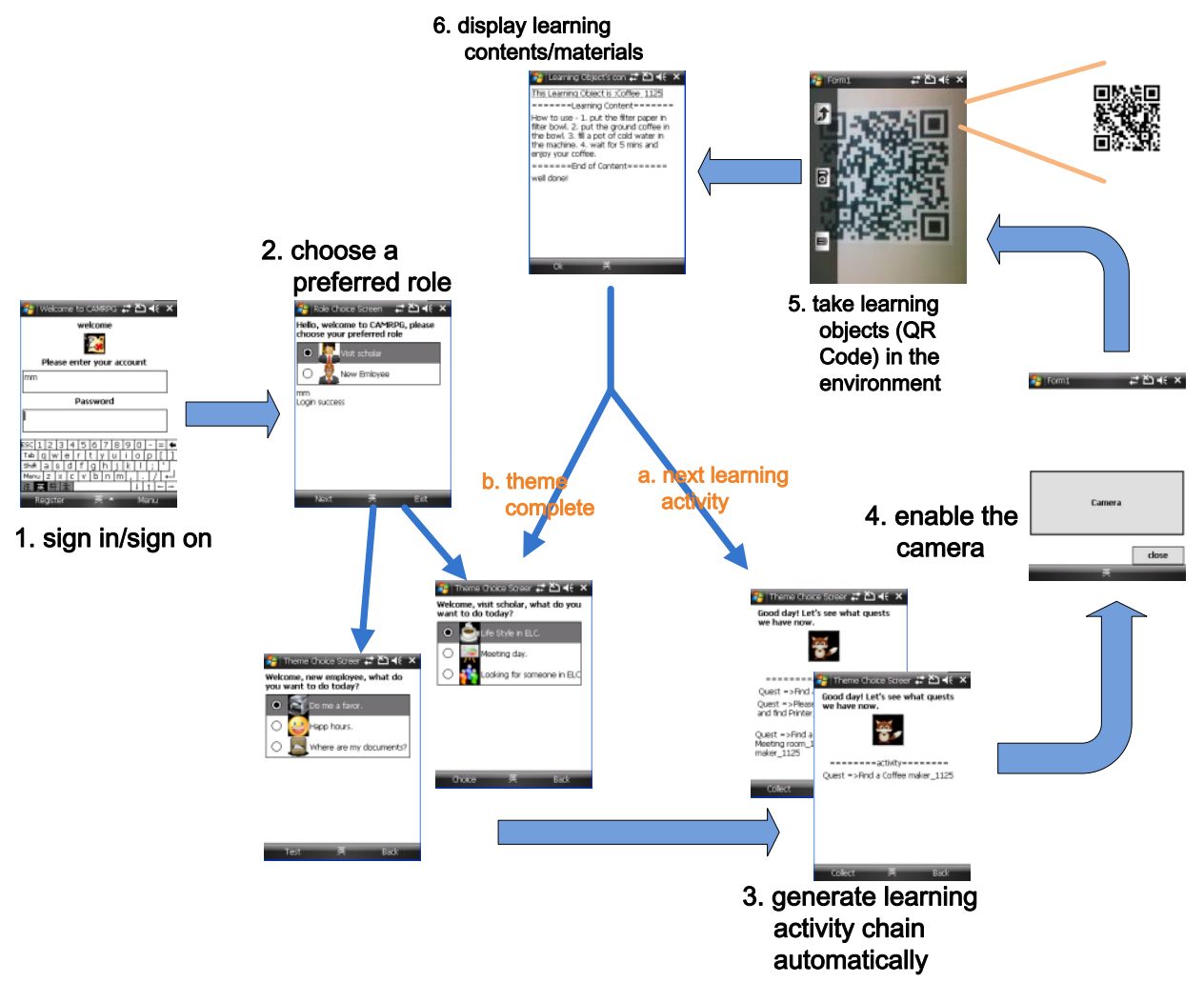

Figure 9. Screenshots of the game-play

In current version of the game, two roles and corresponding pre-defined themes are designed. For instances, a visiting scholar may have interest in the life style of the new environment $\mathrm{s} / \mathrm{he}$ has just arrived in and a new employee may want to know people's offices and specific working procedures (as Step 2 on Figure 9 shows). After the Learning Activity Generator sends the learning activity chain to the Player Agent, the 
Player Agent displays the learning activity to the user one by one as Step 3 on Figure 9 shows. Subsequently, the Activity Item Collector enables the built-in camera for the user and decodes the QR code photo that the user took (as Step 4 and 5 on Figure 9 shows). Step 6 on Figure 9 shows text-based learning material of specific learning object. Beside text-based learning contents, the learning contents can also be HTML-based, binarybased image, an URL of webpage, media stream and Flash animation to deliver different types of information/knowledge to the user.

At last, the Player Agent judges if the collected item is what the learning activity asks for (as Step A and Step B on Figure 9 show). In the whole process, these agents are collaborative working together to provide the user context-awareness learning activities and mobile game-based learning experiences. The multi-agent based system makes the game easier to design, develop, and alter/replace functions.

\section{Usability Analysis}

This research did a pilot study to evaluate the usability of the proposed mobile educational game. This section starts from talking the design of pilot study and questionnaire; then, proposing research questions (i.e., the hypothesis); and describing the usability analysis results and discussing the findings at the end.

\subsection{Usability Questionnaire and Hypothesis}

The pilot study took place in the Department of Information Management (IM) of National Kaohsiung First University of Science and Technology (NKFUST). The proposed game here in this study is to help new students get familiar with the environment by playing this mobile role playing game. Before started the study, researchers constructed the ubiquitous knowledge structure for the working and learning environment of the department. With the GPS and QR Codes' help, the proposed game can store knowledge and information for more than one place, which means, the users can play the game at different places.

\section{A. Participant and Procedure}

The participants of this pilot study are 37 st year graduate students of the department including 25 male and 12 female students. The pilot study was holding in the mid of September, 2010. At that moment, all students are new to the department, so them have difficulty with this new environment (i.e., new school, new policy, new campus, and new faces) and are qualified to our research assumption and objective, that is "users can get familiar with the new working environment and learn new procedure and work flow by playing mobile educational game."

Leaflets or brochures definitely can provide these students some information and knowledge about the school and the department. However, we can imagine how heavy the brochure may be if we want the brochure covering too much knowledge. We can imagine how the students feel about the heavy brochure. Will they really like to read it? We don't think so. Also, the leaflets and brochures are neither location-awareness nor context-awareness, which means the students need to find the knowledge which they think it is useful to them by digging and searching the whole brochure from time to time. Moreover, if they want to get to somewhere, they need to know where they are first on the static map in the brochure. 
The pilot study took one week. At beginning, the researchers introduced the game in class; then the researchers invited students playing the game; at the end, the researchers delivered the questionnaire to the participants and asked them to fill it.

\section{B. Usability Questionnaire}

As mentioned in Section 2, a system with good usability will "be easy to learn", "be efficient to use", "be easy to remember", "has few errors", and "be subjectively pleasing" (Nielson, 1993). We develop the usability questionnaire according to these five features that a system with good usability has as well as the three concepts (i.e. effectiveness, efficiency and satisfaction) that are specified in ISO 9241-11:

- How easy the system is to users to complete tasks when they use the system first time? [Easy to Learn]

- How quickly can users complete tasks once they have learned the user interface of the system? [Efficient to Use]

- After users don't use the system for a while, how easily can they recall how to use the system? [Easy to Remember]

- How many system errors the users may encounter while using the system? [Few Errors]

- How easily can the users go through the system errors? [Few Errors]

- How pleasant the users are going to have after using the system? [Subjectively Pleasing]

- How accurate information the system can provide users to help users complete specific tasks? [Effectiveness]

- How complete the system is designed for helping users to complete specific tasks well? [Effectiveness]

- How much time the system spends on providing required resources to users? [Efficiency]

- Can the procedure that the system uses saving users' time compared to the original procedure? [Efficiency]

- How relevant the resources are that the system provides to users for completing specific goals? [Efficiency]

- How sufficient the resources are that the system provides to users? [Efficiency]

- How comfortable the users feel toward the system after using it? [Satisfaction]

- How helpful the users feel toward the system after using it? [Satisfaction]

- Will the users choose to use the system again in the future? [Satisfaction]

Seong (2006) has proposed ten usability guidelines for mobile learning portal design. These guidelines can be categorized into three aspects: user analysis, interaction, and interface design. This research takes several guidelines from Seong's research to design the usability questionnaire, e.g., "visibility of the status", "minimize human cognitive load", "small screen display", and "consistency". 
Table 1. Questionnaire and Factors Affect System's Usability

\begin{tabular}{|c|c|c|c|}
\hline & Item ${ }^{*}$ & \multicolumn{2}{|c|}{ Factors Affect System's Usability } \\
\hline 1 & $\begin{array}{l}\text { This system's user interface is easy to } \\
\text { use. }\end{array}$ & \multirow[t]{2}{*}{ Easy to use } & \multirow{6}{*}{ Effectiveness } \\
\hline 2 & Using this system is easy to me. & & \\
\hline 3 & $\begin{array}{l}\text { The system procedure is clear and } \\
\text { simple to me. }\end{array}$ & Intuitively Appearance & \\
\hline 4 & $\begin{array}{l}\text { The terms and functions on the system } \\
\text { are easy to understand. }\end{array}$ & $\begin{array}{l}\text { Visibility of system } \\
\text { status }\end{array}$ & \\
\hline 5 & $\begin{array}{l}\text { The logical design of this system is } \\
\text { good, I have no difficulty in using it. }\end{array}$ & Consistency & \\
\hline 6 & $\begin{array}{l}\text { I can learn how to use this system } \\
\text { easily. }\end{array}$ & Easy to learn & \\
\hline 7 & $\begin{array}{l}\text { I can get needed information quickly } \\
\text { by using this system. }\end{array}$ & \multirow{3}{*}{ Efficient to use } & \multirow{5}{*}{ Efficiency } \\
\hline 8 & $\begin{array}{l}\text { The generated learning activities can } \\
\text { save my time in learning. }\end{array}$ & & \\
\hline 9 & $\begin{array}{l}\text { I can get familiar with the learning } \\
\text { objects (i.e. devices, room places, } \\
\text { items) quickly by using this system. }\end{array}$ & & \\
\hline 10 & $\begin{array}{l}\text { This system provides me enough } \\
\text { information for what I want to know. }\end{array}$ & Relevant information & \\
\hline 11 & $\begin{array}{l}\text { This system provides me enough } \\
\text { information for learning (i.e. learning } \\
\text { objects and relevant knowledge). }\end{array}$ & Quantity of information & \\
\hline 12 & $\begin{array}{l}\text { Using this system make me adapt to } \\
\text { the new environment. }\end{array}$ & \multirow[b]{2}{*}{ Reduce cognitive load } & \multirow{7}{*}{ Satisfaction } \\
\hline 13 & $\begin{array}{l}\text { Using this system improves my } \\
\text { learning performance in the new } \\
\text { environment. }\end{array}$ & & \\
\hline 14 & $\begin{array}{l}\text { I will recommend others to use this } \\
\text { system. }\end{array}$ & Subjectively pleasing & \\
\hline 15 & $\begin{array}{l}\text { I can complete the learning activities } \\
\text { that system offers by traveling in the } \\
\text { new environment. }\end{array}$ & $\begin{array}{l}\text { Match between system } \\
\text { and the real world }\end{array}$ & \\
\hline 16 & $\begin{array}{l}\text { The information provided by this } \\
\text { system is correct. }\end{array}$ & \multirow{2}{*}{$\begin{array}{l}\text { Reliability } \\
\text { availability }\end{array}$} & \\
\hline 17 & $\begin{array}{l}\text { The information provided by this } \\
\text { system can be trusted. }\end{array}$ & & \\
\hline 18 & $\begin{array}{l}\text { I want to use this system for learning } \\
\text { tool in the future. }\end{array}$ & Intention & \\
\hline
\end{tabular}

*: Five-point Likert-scale items: 1 for strongly disagree to 5 for strongly agree

Eighteen five-point Likert-scale items ( 5 for "strongly agree" to 1 for "strongly disagree") had been designed for the usability questionnaire in this study. The questionnaire addresses thirteen factors which may affect a system's usability in the three dimensions described in ISO 9241-11, i.e., effectiveness, efficiency, and satisfaction. The validity of these items was established by a review of three experts in educational technology field. Selected items were revised based upon their comments and recommendations. The Cronbach's alpha for the overall questionnaire is 0.88 indicating 
that the questionnaire (and its items) can be seen as reliable due to its internal consistency is good enough (i.e., exceeds.0.75) (Hair, Anderson, Tatham, \& Black, 1995). Table 1 lists the questionnaire items, the thirteen factors and corresponding three dimensions.

\section{Research Questions}

The researchers want to find the answers of the following questions by analyzing the collected data of this pilot study:

(1) Does the proposed context-aware mobile educational game's usability good enough to users?

(2) Does the effectiveness of using context-aware mobile educational game to male and female participants be different?

(3) Does the efficiency of using context-aware mobile educational game to male and female participants be different?

(4) Does the satisfaction of using context-aware mobile educational game to male and female participants be different?

\subsection{Results and Analysis}

\section{A. Descriptive Statistics}

The 18-item questionnaire covers thirteen factors which can be used to examine the usability of a system as we talked earlier. Table 2 lists the descriptive statistics of the thirteen factors for different gender groups. The overall scores that female participants responded are higher than male participants. Especially to the "Easy to Learn" and "Intention" factors, the mean values of "Easy to Learn" factor is 4.58 and "Intention" factor is 4.5 are much higher than the males' 3.76 and 3.68. In addition, the factor has the lowest mean value that male participants responded is "Visibility of System Status" compared to females' "Relevant information". We will discuss these results in details next section. Next, we use independent T-test to see if there is gender difference to the three dimensions and thirteen factors individually.

\section{B. Gender Differences}

\section{Independent T-test for the three concepts}

The statistical analysis data in Table 3 shows that there are significant differences between male and female participants for two dimensions: Effectiveness $(p<0.05)$ and Satisfaction $(\mathrm{p}<0.05)$. The results indicate that male and female participants feel quite differently to the effectiveness of the proposed mobile educational game. Similarly, they also have different degrees of satisfaction to the proposed game. There is no difference between male and female participants' responses regarding the efficiency of the proposed game.

\section{Independent T-test for the thirteen factors}

We further explore to see if there is gender difference in the thirteen factors that may affect system's usability. As the results in Table 4 show, there are significant differences between male and female participants to "Easy to Learn" factor $(\mathrm{p}<0.001)$ and "Intention" factor $(p<0.01)$. Beside the two factors, the gender differences for another three factors - "Subjectively Pleasing" ( $p=0.079)$, "Match between System and Real World" $(p=0.062)$ and "Reliability and Availability" $(p=0.073)$ can also be told from 
Table 4. The statistical analysis of the rest eight factors shows there is no obviously difference between male and female participants' responses.

Table 2. The descriptive statistics of the thirteen factors that may affect system's usability

\begin{tabular}{|c|c|c|c|c|}
\hline & Gender & Quantity & Mean & $\begin{array}{l}\text { Standard } \\
\text { deviation }\end{array}$ \\
\hline \multirow[t]{2}{*}{ 1. Easy to Use } & female & 12 & 4.1250 & .74239 \\
\hline & male & 25 & 4.0000 & .61237 \\
\hline \multirow[t]{2}{*}{ 2. Intuitively Appearance } & female & 12 & 4.1667 & .93744 \\
\hline & male & 25 & 3.8800 & .78102 \\
\hline \multirow[t]{2}{*}{ 3. Visibility of System Status } & female & 12 & 4.0000 & 1.04447 \\
\hline & male & 25 & 3.5600 & .76811 \\
\hline \multirow[t]{2}{*}{ 4. Consistency } & female & 12 & 4.3333 & .77850 \\
\hline & male & 25 & 3.9200 & .64031 \\
\hline \multirow[t]{2}{*}{ 5. Easy to Learn } & female & 12 & 4.5833 & .51493 \\
\hline & male & 25 & 3.7600 & .52281 \\
\hline \multirow[t]{2}{*}{ 6. Efficient to Use } & female & 12 & 4.4722 & .62697 \\
\hline & male & 25 & 4.1600 & .57025 \\
\hline \multirow[t]{2}{*}{ 7. Relevant Information } & female & 12 & 3.9167 & .90034 \\
\hline & male & 25 & 3.8000 & .81650 \\
\hline \multirow[t]{2}{*}{ 8. Quantity of Information } & female & 12 & 4.0000 & .85280 \\
\hline & male & 25 & 3.6800 & .74833 \\
\hline \multirow[t]{2}{*}{ 9. Reduce Cognitive Load } & female & 12 & 4.0000 & .56408 \\
\hline & male & 25 & 3.5800 & .98615 \\
\hline \multirow[t]{2}{*}{ 10. Subjectively Pleasing } & female & 12 & 4.2500 & .62158 \\
\hline & male & 25 & 3.7600 & .83066 \\
\hline \multirow[t]{2}{*}{$\begin{array}{l}\text { 11. Match between System and Real } \\
\text { World }\end{array}$} & female & 12 & 4.4167 & .66856 \\
\hline & male & 25 & 3.8000 & 1.00000 \\
\hline \multirow[t]{2}{*}{ 12. Reliability and Availability } & female & 12 & 4.1667 & .38925 \\
\hline & male & 25 & 3.7600 & .70887 \\
\hline \multirow[t]{2}{*}{ 13. Intention } & female & 12 & 4.5000 & .52223 \\
\hline & male & 25 & 3.6800 & .80208 \\
\hline
\end{tabular}


Table 3. T-test for dimensions of system usability

\begin{tabular}{|l|l|l|l|l|l|l|l|}
\hline & \multicolumn{6}{l}{$\begin{array}{l}\text { Levene's Test for } \\
\text { Equality } \\
\text { Variances }\end{array}$} & \multicolumn{6}{l|}{ of } & \multicolumn{6}{l|}{ T-test for equality of means } \\
\hline & $\begin{array}{l}\text { F- } \\
\text { test }\end{array}$ & significance & t & DF & $\begin{array}{l}\text { Significance } \\
\text { (two-tailed) }\end{array}$ & $\begin{array}{l}\text { Mean } \\
\text { Differences }\end{array}$ & $\begin{array}{l}\text { Std. Error } \\
\text { Differences }\end{array}$ \\
\hline Effectiveness & 3.179 & .083 & 2.185 & 35 & $\mathbf{. 0 3 6}^{*}$ & .36889 & .16886 \\
\hline Efficiency & 1.273 & .267 & 1.470 & 35 & .150 & .27467 & .18682 \\
\hline Satisfaction & 1.778 & .191 & 2.339 & 35 & $\mathbf{. 0 2 5}^{*}$ & .51143 & .21866 \\
\hline
\end{tabular}

Table 4. T-test for factors of system usability (only list important factors)

\begin{tabular}{|l|l|l|l|l|l|}
\hline & \multicolumn{2}{|l|}{$\begin{array}{l}\text { Levene's Test for } \\
\text { Equality } \\
\text { Variances }\end{array}$} & \multicolumn{4}{l|}{ T-test for equality of means } \\
\hline & F-test & significance & $\mathrm{t}$ & DF & $\begin{array}{l}\text { Significance (two- } \\
\text { tailed) }\end{array}$ \\
\hline Easy to Learn & .492 & .488 & 4.505 & 35 & $.000^{* *}$ \\
\hline $\begin{array}{l}\text { Subjectively } \\
\text { Pleasing }\end{array}$ & .826 & .370 & 1.809 & 35 & $\mathbf{. 0 7 9}$ \\
\hline $\begin{array}{l}\text { Match between } \\
\text { System and Real } \\
\text { World }\end{array}$ & .755 & .391 & 1.932 & 35 & $\mathbf{. 0 6 2}$ \\
\hline $\begin{array}{l}\text { Reliability and } \\
\text { Availability }\end{array}$ & 3.307 & .078 & 1.849 & 35 & $\mathbf{. 0 7 3}$ \\
\hline Intention & 1.299 & .262 & 3.217 & 35 & $.003^{* *}$ \\
\hline
\end{tabular}

\subsection{Finding and Discussion}

There are some interesting findings from the pilot study and these findings can help us understanding the usability of the proposed mobile educational game as well as answering the abovementioned four research questions. For the first question, as the statistical data in Table 2 shows, the responses from both male and female participants highly appreciation to the proposed context-aware mobile educational game in every way. In addition, female participants' responses to all factors are relatively higher than male participants in this pilot study. Some factors show relatively low mean values include "Visibility of System Status", "Relevant Information", and "Quantity of Information" tell us the direction that the game can be improved to provide users more richness and variety of learning activities.

Some researchers have done research in reflecting male and female players' behaviors and attitudes toward the game-based learning. Their results also show that 
males tend to feel the educational games are boring, in the contrary, females have more positive perceptions toward the educational games (Gwee, Chee, \& Tan, 2010; Law, 2010). For the effectiveness question, we also found that male and female participants do have different feelings of the effectiveness of the proposed game. Both male and female participants feel that using context-aware mobile educational game is easy, but female participants rate it higher than male participants do. The Effectiveness dimension has five factors as Table 1 lists. To the "Easy to Learn" factor, female participants feel that it is easy to learn how to play the game.

Papastergiou (2009) has applied digital gamed-based learning in computer science education and found that there is no significant difference between male and female participants' perceptions toward the overall appeal, the user interface's quality, and the game-play's educational value. For the efficiency question, the results also show no significant differences between male and female participants. Nevertheless, the responses still provide us thoughts on how to improve the proposed game in the future. For instance, both males and females are not so agree that the game provides them enough information, i.e., the mean value of "Relevant Information" factor is relatively lower than other factors. We should further explore to see whether this perception came from the generated learning activities didn't fit to users' demands or came from the game gave the users not enough information regarding the learning objects involved in the generated learning activities. This usability questionnaire provides our research a guideline for the next step of system upgrade.

Wang and colleagues (2009) find that performance expectancy and effort expectancy are significant determinants of the behavioral intention to use mobile learning systems. In this pilot study, for the satisfaction question, similar to the results of the effectiveness question, the data of the satisfaction dimension also shows that female participants have higher intention toward the proposed game than males and confirms that the effectiveness does play a significant determinant of the behavioral intention to use a system.

Several disadvantages exist in this pilot study. First of all, due to the limit participants, the sample size for the statistics may not achieve a proper size in this pilot study. Second, in this pilot study, we focused on usability analysis of the proposed system due to "the usability analysis is needed to any software project", as Nielsen and other researchers said. Both usability analysis and comparative analysis are important to the proposed game, and we believe these two analyses can be done separately without problem. If the game is not better, then it is unnecessary to discuss its usability. Similarly, if the users feel the game's usability is less, then they will not have interest in using it even we (researchers) promo it hardly. Which we see it happens all the time when we (researchers) want to ask users (teachers or students) using our research outcome. So, we decided to make sure that the proposed game has high enough usability to the users first. In the other words, this study has no comparative analysis in assessing if the proposed game is better to users than the traditional way. Since we have got positive results in usability analysis, we are now considering to touch base with business and to arrange possible experiment in comparing the proposed system with traditional orientation way of trainings.

\section{Conclusions and Future Works}

In this paper, we present a multi-agent-based mobile educational game in which the kernel, learning activity generating engine, can generate context-awareness learning 
activities automatically. This game can help users doing on-the-job training to get familiar with new environment; to adapt new working procedure and policy; and, to learn facilities related to jobs. The proposed game has three features: (1) it has contextawareness knowledge structure to store all learning objects and characteristics associated with the environment; (2) it can generate different learning activity chains according to user's location, chosen role and theme, and surrounding learning objects; (3) its multiagent architecture makes itself easy to maintain and to extend. We have done a pilot study and design a questionnaire to assess the usability of the proposed game. The results show that female participants give higher scores in all factors of assessing a system's usability than male participants. Correspondingly, we found significant differences between male and female participants in the factors "Easy to Learn" and "Intention".

We still have two research issues needed to be done further: storytelling and reward. The learning activity in this game is boring in some sense, the activity currently only asks the user to find specific learning object. The pilot study also gives us statistical evidence on the male participants' responses. At next stage, we are going to put narrative elements and storytelling strategies into the learning activity generation process. The story-based learning activity may make users feel they are playing game rather than following orders made by the Player Agents. Reward is very important to motivate people, e.g., students study in schools and employees do jobs in workplaces. Rewards can be real or virtual ones, many researchers argue virtual rewards are better. In the proposed game, we do have reward for every learning activity. However, the rewards currently have no significant meaning to the user. At next stage, we may need to make the rewards more valuable to the users.

\section{Acknowledgments}

The authors wish to acknowledge the support of NSERC, iCORE, Xerox and the research related gift funding provided to the Learning Communities Project by Mr. Allan Markin.

\section{References}

1. Baylor, A.L. (1999). Intelligent agents as cognitive tools for education. Educational Technology, 39(2), 36-40.

2. Brown, J.S., Collins, A., \& Duguid, P. (1989). Situated cognition and the culture of learning. Educational Researcher, 18(1), 32-42.

3. Cacallari, B., Hedberg, J., \& Harper, J. (1992). Adventure Games in Education: A Review. Australian Journal of Educational Technology, 8(2), 172-184. 1992.

4. Chang, C., Wu, S., Chang, M., \& Heh., J.-S. (2008). Activity generator for informal learning in museum. In the Proceedings of the 7th WSEAS International Conference on E-ACTIVITIES, (E-ACTIVITIES 2008), Dec 29-31, Cairo, Egypt, 189-194.

5. Chang, A., \& Chang, M. (2006). A Treasure Hunting Learning Model for Students Studying History and Culture in the Field with Cellphone. In the Proceedings of the 6th IEEE International Conference on Advanced Learning Technologies, (ICALT 2006), Kerkrade, The Netherlands, July 5-7, 2006,106-108.

6. Chen, Y.-S., Kao, T.-C., Yu, G.-J., \& Sheu, J.-P. (2004). A Mobile ButterflyWatching Learning System for Supporting Independent Learning. In the Proceedings of the IEEE International Workshop on Wireless and Mobile 
Technologies in Education, (WMTE 2004), March 23-25, 2004, Chung-Li, Taiwan, 11-18.

7. Corti, K. (2006). Game-based learning: A serious business applications. Retrieved March 24, 2010, from http://pixelearning.com/docs/games_basedlearning_pixelearning.pdf.

8. Dutchuk, M., Muhammadi, K.A., \& Lin, F. (2009). QuizMASter - A multi-agent game-style learning activity. In the Proceedings of the 4th International Conference on E-Learning and Games, (Edutainment 2009), August 9-11, Banff, Canada. 263-272.

9. Düntsch, I., \& Gediga, G. (1998). Uncertainty measures of rough set prediction. Artificial Intelligence, 106(1), 109-137.

10. Fisher, K.M. \& Hoffman, R. (2003). Knowledge and semantic network theory. San Diego: Semantic Research, Inc. Retrieved March 24, 2010, from http://www.semanticresearch.com/downloads/whitepapers/theory whitepaper.pdf.

11. Fetaji, M., Dika, Z., \& Fetaji, B. (2008). Usability testing and evaluation of a mobile software solution: A case study. In the proceedings of the 30th International Conference on Information Technology Interfaces (ITI 2008). June 23-26, 2008, Dubrovnik, 501 - 506

12. Frazer, A., Argles, D., \& Wills, G. (2008). The Same, But Different: The Educational Affordances of Different Gaming Genres. In the Proceedings of the 8th IEEE International Conference on Advanced Learning Technologies, (ICALT 2008), Santander, Cantabria, Spain, July 1-5, 2008, 891-893.

13. Gwee, S., Chee, Y.-S., \& Tan, E.-M. (2010). Spatializing Social Practices in Mobile Game-Based Learning, In the proceeding of 10th IEEE International Conference on Advanced Learning Technologies, (ICALT 2010), July 05-07, Sousse, Sousse Tunisia, 555-557.

14. Garris, R., Ahlers, R., \& Driskell, J. (2002). Games, motivation, and learning: A research and practice model. Simulation and Gaming, 33(4), 441-467.

15. Hair, J.F., Anderson, R.E., Tatham, R.L., \& Black, W.C. (1995). Multivariate Data Analysis (5th ed.). Upper Saddle River, NJ: Prentice Hall.

16. Holzinger, A. (2005). Usability Engineering for Software Developers. Communications of the ACM, 48(1), 71-74

17. Hussain, A., \& Ferneley, E. (2008). Usability metric for mobile application: A goal question metric (GQM) approach. In the Proceedings of the 10th International Conference on Information Integration and Web-based Applications \& Services, (iiWAS 2008), Linz, Austria, November 24-26, 567-570.

18. ISO/IEC. (1998). Ergonomic Requirements for Office Work with Visual Display Terminals (VDT)s - Part 11 Guidance on Usability. Geneva.

19. Kim, H.-J., \& Schliesser, J. (2007). Adaptation of Storytelling to Mobile Entertainment Service for Site-Specific Cultural and Historical Tour. In the Proceedings of 14th International Conference on Information and Communication Technologies in Tourism, (ENTER 2007), January 24 - 26, 2007, Ljubljana, Slovenia, Vol. 3, 97-108.

20. Kurti, A., Milrad, M., \& Spikol, D. (2007). Designing Innovative Learning Activities Using Ubiquitous Computing. In the Proceedings of the 7th IEEE International Conference on Advanced Learning Technologies, (ICALT 2007), Niigata, Japan, July 18-20, 2007, 386-390. 
21. Law, E.L. (2010). Learning Efficacy of Digital Educational Games: The Role of Gender and Culture. In the Proceedings of the AACE 20th World Conference on Educational Multimedia, Hypermedia and Telecommunications, (ED-Media 2010), June 29-July 2, Toronto, Canada, 3124-3133.

22. Liu, C.-L., Kuo, R., Chang, M., \& Heh, J.-S. (2008). Generating Interest-based Learning Paths based on Information Theory. In the Proceedings of the AACE 20th World Conference on Educational Multimedia, Hypermedia \& Telecommunications, (ED-MEDIA 2008), June 30-July 4, Vienna, Austria, 42354242.

23. Malone, T.W. (1981). What makes computer games fun? Byte, 6(12), 258-277.

24. Nielsen, J. (1993). Usability Engineering. San Francisco, USA: Morgan Kaufman.

25. Novak, J.D. \& Cañas, A.J. (2006). The theory underlying concept maps and how to construct them. Technical Report IHMC CmapTools, Florida Institute for Human and Machine Cognition, January. Retrieved March 24, 2010, from http://cmap.ihmc.us/Publications/ResearchPapers/TheoryUnderlyingConceptMaps. pdf.

26. Novak, J.D., \& Gowin, D.B. (1984). Learning how to learn. New York, NY: Cambridge University Press.

27. Ogata, H., \& Yano, Y. (2005). Knowledge awareness for a computer-assisted language learning using handhelds. International Journal of Continuous Engineering Education and Lifelong Learning, 14(4/5), 435-449.

28. Papastergiou, M. (2009).Digital Game-Based Learning in High School Computer Science Education: Impact on Educational Effectiveness and Student Motivation. Computers \& Education, 52(1), 1-12.

29. Pawlak, Z., \& Skowron, A. (2007). Rough sets: Some extensions. Information Science, 177(1), 28-40.

30. Pettey, C., \& Goasduff, L. (2011). Gartner Says Worldwide Mobile Device Sales to End Users Reached 1.6 Billion Units in 2010; Smartphone Sales Grew 72 Percent in $2010 \quad$ Retrieved March 24, 2011, from http://www.gartner.com/it/page.jsp?id=1543014.

31. Pivec, M., Dziabenko, O., \& Schinnerl, I. (2003). Aspects of game-based learning. In the Proceedings of the 3rd International Conference on Knowledge Management, (I-KNOW 2003), Graz, Austria, July 2-4, 2003, 216-225.

32. Quillian, M.R. (1967). Word concepts: A theory and simulation of some basic semantic capabilities. Behavioral Science, 12(5), 410-430.

33. Seong, D.S.-K. (2006). Usability guidelines for designing mobile learning portals. In the Proceedings of the 3rd international conference on Mobile technology, applications \& systems, October 25-27, Bangkok, Thailand. Article No. 25

34. Shannon, C.E. (1948). A Mathematical Theory of Communication. Bell System Technical Journal, 27, 623-656.

35. Sowa, J.F. (1983). Conceptual Structures: Information Processing in Mind and Machine. Addison-Wesley, Reading, MA.

36. Tan, Q., \& Kinshuk. (2009). Client Mobile Software Design Principles for Mobile Learning Systems. International Journal of Interactive Mobile Technologies, 3(1), 32-37. 
37. Wang, Y.-S., Wu, M.-C., Wang, H.-Y. (2009). Investigating the Determinants and Age and Gender differences in the Acceptance of Mobile Learning. British Journal of Educational Technology, 40(1), 9-118.

38. Wu, S., Chang, A., Chang, M., Liu, T.-C., \& Heh, J.-S. (2008). Identifying personalized context-aware knowledge structure for individual user in ubiquitous learning environment. In the Proceedings of the 5th IEEE International Conference on Wireless, Mobile, and Ubiquitous Technologies in Education, (WMUTE 2008), Beijing, China, March 23-26, 2008, 95-99.

39. Wu, S., Chang, A., Chang, M., Yen, Y.-R., \& Heh., J.-S. (2010). Learning Historical and Cultural Contents via Mobile Treasure Hunting in Five-harbor District of Tainan, Taiwan. In the Proceedings of the 6th IEEE International Workshop on International Conference on Wireless, Mobile, and Ubiquitous Technologies in Education, (WMUTE 2010), Kaohsiung, Taiwan, April 12-16, 2010, 213-215.

40. Wu, T.-T., Yang, T.-C., Hwang, G.-J., \& Chu, H.-C. (2008). Conducting situated learning in a context-aware ubiquitous learning environment. In the Proceedings of the 5th IEEE International Conference on Wireless, Mobile and Ubiquitous Technologies in Education, (WMUTE 2008), Beijing, China, March 23-26, 2008, 82-86.

41. Zhang, L., \& Lin, Q. (2007). MACVE: A mobile agent based framework for largescale collaborative virtual environments. Teleoperators \& Virtual Environments, 16(3), 279-292. 